\title{
Correction to: Towards the conservation of the Mesozoic relict fern Christensenia: a fern species with extremely small populations in China
}

\author{
Hongmei Liu ${ }^{1} \cdot$ Harald Schneider $^{2} \cdot$ Ying Yu $^{3} \cdot$ Tao Fujiwara $^{2} \cdot$ Phyo Kay Khine ${ }^{2}$
}

Published online: 10 October 2019

(c) The Botanical Society of Japan and Springer Japan KK, part of Springer Nature 2019

\section{Correction to: \\ Journal of Plant Research (2019) 132:601-616 \\ https://doi.org/10.1007/s10265-019-01131-9}

In the original publication of the article, one of the author names, "Tao Fuijwara” was published incorrectly. The correct name is Tao Fujiwara.

The original article can be found online at https://doi.org/10.1007/ s10265-019-01131-9.

Hongmei Liu

liuhongmei@xtbg.ac.cn

1 CAS Key Laboratory of Tropical Plant Resources and Sustainable Use, Xishuangbanna Tropical Botanical Garden, Chinese Academy of Sciences, Menglun 666303, Yunnan, China

2 Center for Integrative Conservation, Xishuangbanna Tropical Botanical Garden, Chinese Academy of Sciences, Menglun 666303, Yunnan, China

3 College of Life and Environmental Sciences, Hangzhou Normal University, Hangzhou 310036, China 